\title{
La intervención local en las viviendas de uso turístico a través de la zonificación urbanística: requisitos y consecuencias
}

\section{Local government intervention in housing for tourist use through urban zoning: requirements and consequences}

\author{
Estanislao Arana García \\ Universidad de Granada \\ earana@ugr.es
}

\section{NOTA BIOGRÁFICA}

Doctor en Derecho por la Universidad de Granada. Catedrático de Derecho administrativo en la Universidad de Granada. Principales líneas de investigación: Derecho urbanístico y ambiental, Derecho administrativo económico, Derecho de aguas.

\section{RESUMEN}

Con orígenes en formas colaborativas de economía no guiadas por el ánimo de lucro, en los últimos años ha surgido un nuevo modelo de servicios turísticos conocido bajo expresiones como la de «alojamientos turísticos» o "viviendas turísticas». Se trata de viviendas de carácter inicialmente residencial que, a través de una plataforma digital, son ofertadas con carácter turístico. Se trata de una actividad económica con mucha aceptación social pero que, sin embargo, está generando numerosos conflictos relacionados, por ejemplo, con el medio ambiente urbano. Las Comunidades Autónomas, en el ejercicio de sus competencias en materia de turismo, han dictado normas que limitan esta actividad. Además, por otra parte, los Ayuntamientos, en ejercicio de sus competencias urbanísticas, están llevando a cabo una importante labor de control y limitación de la actividad a través de la técnica de la zonificación y que supone ubicar este tipo de viviendas en determinadas y concretas partes de la ciudad. A analizar los problemas jurídicos que se plantean con este tipo de medidas se dedica este trabajo.

\section{PALABRAS CLAVE}

Economía colaborativa; alojamientos turísticos; viviendas turísticas; medio ambiente urbano; zonificación; calificación urbanística; libre prestación de servicios; directiva de servicios; urbanismo y medio ambiente; dotaciones e infraestructuras locales.

\footnotetext{
ABSTRACT

Originally based on collaborative forms of economy not guided by the search of profit, in recent years a new model of tourism services known such as «tourist accommodation» or «tourist housing» has emerged. This model is orientend to residential housing and owners that, through digital services, is offered for touristic purposes. As economic activity with great social acceptance, nevertheless it is generating numerous conflicts related, for example, to the urban environment. The Autonomous Communities in the exercise of their competences in the tourism framework have approved regulations that limit this activity. On the other hand, the municipalities in the exercise of their urban competences are carrying out a major control and limitation of the activity through of zonification and locating this type of housing in specific areas of the city. This paper analyzes the legal perspective of this topic and how this type of measures and businesses are being development.
} 
REALA. Nueva Época - N. ${ }^{10}$, Octubre 2018 - ISSN: 1989-8975 - DOI: 10.24965/reala.v0i10.10545 - [Págs. 6-21]

La intervención local en las viviendas de uso turístico a través de la zonificación urbanística: requisitos y consecuencias

Estanislao Arana García

\section{KEYWORDS}

Collaborative economy; tourist accommodation; tourist and housing economy; urban environmental planning and zonification; urban administrative authorization; freedom to provide services; directive of services; urban planning and environmental protection; local areas and infrastructures.

\section{SUMARIO}

I. INTRODUCCIÓN. II. LAS COMPETENCIAS URBANÍSTICAS MUNICIPALES COMO TÍTULO DE INVERVENCIÓN EN EL ALOJAMIENTO TURÍSTICO: EN ESPECIAL, LA CALIFICACIÓN O ZONIFICACIÓN COMO TÉCNICA URBANÍSTICA APLICABLE. 1. LA CLASIFICACIÓN Y CALIFICACIÓN URBANÍSTICA COMO TÉCNICAS DELIMITADORAS DEL DERECHO DE PROPIEDAD INMOBILIARIA. 2. DEL ALOJAMIENTO COLABORATIVO AL ALOJAMIENTO TURÍSTICO O VACACIONAL: EL TRÁNSITO DEL USO RESIDENCIAL AL USO TERCIARIO HOTELERO. 3. EL INDETERMINADO Y HETEROGÉNEO RÉGIMEN JURÍDICO DE LA ZONIFICACIÓN O CALIFICACIÓN URBANÍSTICA. 4. LA ZONIFICACIÓN O CALIFICACIÓN URBANISTICA ES UN REQUISITO PARA EL EJERCICIO DE UNA ACTIVIDAD ECONÓMICA Y, POR TANTO, EN FUNCIÓN DE LAS CIRCUNSTANCIAS, PODRÍA CONSIDERARSE UNA MEDIDA CONTRARIA A LA LIBERTAD DE PRESTACIÓN DE SERVICIOS PERO NO DE FORMAAUTOMÁTICA. 5. LOS CAMBIOS DE USO DE RESIDENCIAL A TURÍSTICO Y LA NECESIDAD DE AUMENTO DE LAS DOTACIONES E INFRAESTRUCTURAS. III. CONCLUSIONES.

\section{INTRODUCCIÓN}

La conocida bajo la expresión «economía colaborativa» como mecanismo para el intercambio de bienes y servicios de carácter no profesional, es el germen de una auténtica revolución que tiene lugar en nuestros días con la generación de nuevas actividades económicas que permite prestar determinados servicios muy demandados por la sociedad y con una enorme aceptación por su parte. Quizás, sean los sectores del transporte y del alojamiento turístico o alquiler vacacional los que más clara y globalmente se están viendo afectados por este fenómeno'.

Precisamente, el interés general que hay detrás de estas nuevas formas de economía, reclama una regulación que trate de equilibrar los diferentes derechos e intereses públicos y privados en juego. Es en este punto donde la Administración Pública se ve obligada a intervenir adoptando medidas de control o limitación establecidas en la legislación turística y que pretenden el control del acceso a la actividad en sí o, más recientemente y en el caso de la Administración local, utilizando sus competencias urbanísticas que condicionan absolutamente la actividad en la medida en que se determina el lugar en el que materialmente se puede llevar a cabo esta actividad.

Las medidas urbanísticas que están adoptando gran parte de los Ayuntamientos de nuestro país y que van a ser objeto de análisis en este trabajo, están resultando definitivas a la hora de controlar el desarrollo y expansión del fenómeno del alojamiento turístico o de las viviendas turísticas. Mediante la técnica de la calificación urbanística y de la modificación de los usos del planeamiento se están introduciendo limitaciones muy contundentes al fenómeno del alojamiento turístico que colisionan o pueden colisionar con derechos de carácter individual como la libertad de establecimiento, la propiedad o la libertad de empresa.

Hablamos de un sector realmente importante y con un peso económico nada desdeñable. Según un informe de Exceltur del año de 2015 (suponemos que en la actualidad estas cifras habrán aumentado aún más) el número de camas procedentes del sector del alojamiento turístico (más de 2,7 millones), supera en más del doble a las camas de uso hotelero. En una economía como la española tan dependiente del sector turístico, este fenómeno no puede pasar desapercibido y, de hecho, está siendo objeto de portada casi a diario en los diferentes medios de comunicación del país. La frontera que delimita este nuevo espacio económico, el rasgo definitorio o esencial, lo constituye la ordenación de los mercados por medio de plataformas

1 Para BARNÉS VÁZQUEZ, el fenómeno es tan importante que cabe calificar a la economía colaborativa como la cuarta revolución industrial (pasamos de la era industrial a la era colaborativa). BARNES VÁZQUEZ, J., "Un falso dilema: Taxis vs. Uber", en Diario La Ley, núm. 8.942, 16 de marzo de 2017, pág. 1. 
digitales. Los perfiles los marca la presencia de una empresa que sirviéndose de la tecnología digital opera como un organizador de mercados ${ }^{2}$.

Se trata, sistematizando algunos de los elementos positivos, de un nuevo modelo de servicios turísticos que atiende a una parte de la población que tiene unas necesidades diferentes a las que se ofrecen con los alojamientos turísticos tradicionales. Por ejemplo, es un tipo de turismo que satisface las necesidades de unidades familiares que encuentran en este tipo de alojamiento mayor comodidad y adaptación a sus requerimientos (tanto de espacio como de tiempo de alquiler). Se trata, además, de un tipo de negocio que está al alcance de pequeños propietarios que pueden iniciar una actividad económica (siempre pensando en actividades económicas regularizadas y declaradas fiscalmente) aprovechando bienes y recursos infrautilizados o que, incluso, encuentran un incentivo para la rehabilitación regeneración de los cascos históricos de muchas ciudades de nuestro país. Es lo que se ha venido en denominar la democratización del turismo.

Sin embargo, junto a las ventajas sociales y económicas que tiene esta modalidad de explotación turística, también se producen externalidades que pretenden ser amortiguadas o eliminadas por la acción de los poderes públicos. Tratando de esquematizar o simplificar los efectos negativos de este fenómeno nos encontraríamos con los siguientes: a) problemas de competencia desleal con los operadores tradicionales; b) recelos desde la perspectiva fiscal, laboral y de consumidores; c) saturación del espacio urbano; d) restricciones de acceso al mercado inmobiliario; e) deterioro del medio ambiente urbano; f) incremento de las necesidades de dotaciones, infraestructuras y servicios.

Como en tantos otros sectores el problema está en encontrar la justa medida de intervención pública, tanto el modo como el grado de injerencia de los poderes públicos resultan esenciales para que dicha intervención no genere más problemas de los que trata de resolver. En este sentido, las acciones llevadas a cabo por diferentes municipios utilizando sus potestades y competencias urbanísticas están siendo muy discutidas y polémicas en la medida en que para los defensores de este nuevo modelo de servicios turísticos, son un ejemplo de intervención desenfocada, exagerada y, en muchas ocasiones, arbitraria. Aún siendo necesaria o, cuando menos, conveniente la intervención local en este ámbito, se hace conveniente analizar técnicamente los requisitos necesarios para que las competencias urbanísticas no sean utilizadas en desviación de poder persiguiendo finalidades diferentes a las que el Ordenamiento Jurídico consideró convenientes cuando fueron otorgadas. La solución no puede pasar, por ejemplo, por la prohibición de este tipo de alojamiento en un determinado municipio aludiendo de manera genérica a los problemas que para la convivencia ciudadana provoca. Hay que buscar la regulación más adecuada para que todos los derechos e intereses en juego puedan verse equilibrados. La prohibición es una medida excesivamente simplista y radical que difícilmente puede justificarse o motivarse como la decisión más adecuada tanto por su necesidad como por su proporción.

Podríamos decir que son dos los grupos de Derechos o intereses enfrentados y que hay que armonizar. Por un lado estarían los tradicionales Derechos económicos de raíz más individual como los de propiedad, de libertad de empresa, unidad de mercado y de libre prestación de servicios. Por otra parte, nos encontramos con los Derechos o intereses de carácter general o colectivo como la protección del medio ambiente, el urbanismo y la ordenación del territorio así como otros derechos individuales que también se pueden ver afectados como el de disfrute del domicilio libre de inmisiones ${ }^{3}$.

No va a ser, sin embargo, objeto de atención en este trabajo la regulación autonómica de los alojamientos turísticos que atiende, principalmente, a las reglas de acceso a esta actividad y que ha sido hasta ahora la que despertado más interés por parte de la doctrina científica ${ }^{4}$. Me centraré, exclusivamente, en los

2 HERRERO SUÁREZ, C., "Las viviendas de uso turístico: ¿El enemigo a abatir? Reflexiones sobre la normativa autonómica en materia de alojamientos turísticos", en Revista de Estudios Europeos, núm. 70, julio-diciembre de 2017, pág. 151.

3 SOCÍAS CAMACHO, J. M., "Estado regulador y alojamiento colaborativo. El régimen de la intervención pública limitadora de la prestación del servicio", en Revista de Administración Pública, núm. 205 (2018), pág. 136.

${ }^{4}$ Sobre esta cuestión podemos destacar los siguientes trabajos: RODRIGUEZ FONT, M., "Barreras regulatorias a la economía colaborativa y nuevas vías de impugnación de normas: el caso de las viviendas de uso turístico", en Revista Española de Derecho Administrativo, núm. 182, 2017, págs. 409-444; de la misma autora: "La regulació de l'allotjament col·laboratiu a Catalunya: anàlisi de les propostes de l'Autoritat Catalana de la Competència", en Revista catalana de dret públic, núm. 53, 2016, págs. 163-181; SOCÍAS CAMACHO, J. M., "Estado regulador y alojamiento colaborativo: El régimen de la intervención pública limitadora de la prestación del servicio", en Revista de Administración Pública, núm. 205, 2018, págs. 131-170; LORA-TAMAYO VALLVÉ, M., "Economía colaborativa y alojamiento", en La regulación de la economía colaborativa: Airbnb, BlaBlaCar, Uber y otras plataformas, obra colectiva coordinada por MONTERO PASCUAL, J. J. Ed. Tirant Lo Blanch (2017), págs. 283-325; CONTRERAS DELGADO DE COS, J. M., SILOS RIBAS, M., SOBRINO RUIZ, M., "La economía colaborativa en los sectores regulados (V). Alojamientos turísticos", en la obra colectiva dirigida por ALFONSO SÁNCHEZ, R., VALERO TORRIJOS, J., Retos jurídicos de la economía colaborativa en el contexto digital. Ed. Aranzadi 
REALA. Nueva Época - N. ${ }^{10}$, Octubre 2018 - ISSN: 1989-8975 - DOI: 10.24965/reala.v0i10.10545 - [Págs. 6-21]

La intervención local en las viviendas de uso turístico a través de la zonificación urbanística: requisitos y consecuencias

Estanislao Arana García

aspectos estrictamente locales y urbanísticos de la regulación de esta nueva forma o modalidad de servicios turísticos. Son estos aspectos territoriales los que, realmente, están condicionando la política sectorial turística en este sector. Las medidas más contundentes y, por tanto, polémicas y discutidas en el sector de los alojamientos turísticos ofrecidos a través de plataformas digitales son las que se están tomando desde la ordenación urbanística y territorial.

\section{LAS COMPETENCIAS URBANÍSTICAS MUNICIPALES COMO TÍTULO DE INVERVENCIÓN EN EL ALOJAMIENTO TURÍSTICO: EN ESPECIAL, LA CALIFICACIÓN O ZONIFICACIÓN COMO TÉCNICA URBANÍSTICA APLICABLE}

\section{La clasificación y calificación urbanística como técnicas delimitadoras del Derecho de propiedad inmobiliaria}

El Art. 33 de la Constitución Española de 1978 garantiza el Derecho Fundamental a la propiedad privada pero añadiendo que la función social delimita su contenido, de acuerdo con las leyes. Se trata, como es de sobra conocido, de una concepción del Derecho de propiedad que rompe con la tradición romana del Derecho de propiedad en cuanto Derecho prácticamente ilimitado y cuyo contenido actual sólo se alcanza a comprender desde las limitaciones que, especialmente, la legislación urbanística y el Derecho urbanístico han introducido.

Las instituciones o técnicas que, con las limitaciones y condicionantes establecidos por la legislación urbanística, fijan el estatuto jurídico del Derecho de propiedad del suelo son las de la clasificación y calificación del suelo que sirven para definir el concreto destino previsto para dicha propiedad inmobiliaria. Así lo contempla el Art. 12.1 del vigente Texto Refundido de la Ley del Suelo de 2015: «El derecho de propiedad del suelo comprende las facultades de uso, disfrute y explotación del mismo conforme al estado, clasificación, características objetivas y destino que tenga en cada momento, de acuerdo con la legislación en materia de ordenación territorial y urbanística aplicable por razón de las características y situación del bien» ${ }^{5}$.

La clasificación es la técnica que determina el régimen urbanístico más adecuado a las características de hecho y aptitudes de cada terreno, que opera sobre todo el suelo existente en función de su destino básico, establecido en la normativa urbanística. En la actualidad y desde la legislación básica del Estado, suelos en situación rural o en situación urbanizada y que, según la legislación urbanística autonómica aplicable en cada caso, se corresponderán con la correspondiente clasificación de suelo autonómica. Las clases de suelo más tradicionales y más habituales en la legislación urbanística autonómica son las de urbano, urbanizable y no urbanizable o rústico.

Por su parte, la calificación del suelo supone la atribución a cada suelo de un concreto y específico uso e intensidad que, por tanto, condicionará absolutamente el destino y valor de cada propiedad inmobiliaria. No hay limitaciones respecto al tipo de usos pudiendo el planificador municipal crear los que considere necesarios (dentro del suelo urbano, por ejemplo, tendríamos el uso residencial, el industrial, el terciario, zona verde, etc.)

La clasificación y calificación del suelo son dos de las principales funciones que tiene que cumplir el planeamiento municipal y que conectan de forma necesaria y esencial la función pública de planeamiento con el derecho de propiedad del suelo. De ellas dependerá, por tanto, la estructura de crecimiento de la ciudad y, por otro lado, la configuración de los derechos de los propietarios del suelo ${ }^{6}$.

Por tanto, en definitiva, mediante la clasificación se determina la clase de suelo a que pertenece cada porción concreta del suelo planificado. Mediante la calificación, el correspondiente plan urbanístico decide

(2017), págs. 337-361; GUILLÉN NAVARRO, N. A., "La vivienda de uso turístico y su incidencia en el panorama normativo español", en Revista Aragonesa de Administración Pública, núms. 45-46 (2015), págs. 101-144; RISCOS GÓMEZ, J. F., GARCÍA HIDALGO, J. L., PALMA MARTOS, L., "Mejora de la regulación en la economía colaborativa. El caso de las viviendas turísticas en Andalucía", en Revista Internacional de Turismo y Empresa, vol. 1, núm. 2 (2017).

${ }^{5}$ En términos muy parecidos, se han pronunciado las diferentes leyes del suelo. Así, por ejemplo, los artículos 242.1 y 6 y 243.2 del Texto Refundido de la Ley del Suelo de 1992. El art. 1 del Texto Refundido de la Ley del Suelo de 1976 señalaba que es competencia urbanística «...establecer las zonas distintas de utilización según la densidad de la población que haya de habitarlas, porcentaje de terrenos que pueda ser ocupado por construcciones, volumen, forma, número de plantas, clase y destino de los edificios, con sujeción a ordenaciones generales uniformes para cada especie de los mismos en toda la zona».

6 BUSTILLO BOLADO, R. O., "Clasificación y calificación del suelo”, en MARTín REBOLLO, L., BUSTILLO BOLADO, R. O. (dirs.), Fundamentos de Derecho urbanístico. Ed. Aranzadi, 2007, pág. 388. 
el posible destino urbanístico del territorio mediante la fijación concreta de la clase de uso y destino que corresponde a cada porción de suelo. Con la calificación se ordena definitivamente el terreno ya que se le atribuye un uso específico determinado. Consecuentemente, los usos, actividades o destinos urbanísticos del suelo tienen una importancia trascendental en la configuración y en la evolución de la ciudad, relevancia que se intensifica en el suelo urbano o en situación de urbanizado. La asignación de destinos urbanísticos al suelo forma parte integrante de las funciones del urbanismo y esta trascendental tarea, tras la necesaria habilitación legal estatal y autonómica, corresponde -mayoritariamente- al planificador urbanístico local que es el que tiene la última y más importante palabra a la hora de distribuir los diferentes usos del suelo en un término municipal. De la capacidad del planificador para asignar unos usos adecuados a cada suelo de la ciudad y, sobre todo, de su imaginación para el establecimiento de criterios claros y flexibles para compatibilizar y complementar los diferentes usos entre sí, dependerá la calidad de la ciudad planificada y su capacidad para adaptarse a las nuevas y cambiantes circunstancias y demandas sociales en tanto realidad viva que es ${ }^{7}$. Es habitual, por otra parte, denominar a esta técnica indistintamente, calificación 0 zonificación ${ }^{8}$

En definitiva, los usos del suelo son los concretos destinos urbanísticos que se atribuyen a las zonas que comprenden la ciudad existente. Es decir, las actividades que se pueden desarrollar en cada ámbito del suelo y las que están prohibidas, así como las que, por ser compatibles y/o complementarias, se permiten bajo ciertas condiciones ${ }^{9}$.

La complementariedad de usos es una herramienta muy utilizada por los planificadores municipales para, precisamente, evitar la excesiva rigidez de la planificación urbanística. El establecimiento de usos complementarios pretende evitar la excesiva especialización de uso y la segregación funcional de la ciudad. El principio básico que subyace a la implantación de usos complementarios es la de evitar zonas estancas monofuncionales en la ciudad, buscando la mezcla o interrelación de destinos urbanísticos que se desarrollen en la misma, compatible con una concepción europea de «ciudad compacta» como modelo de ciudad más sostenible ambientalmente en el que no existen núcleos de población aislados y en el que existen usos del suelo complejos y superpuestos en las mismas zonas, prestándose los servicios de forma cercana. Así lo reconoce, por ejemplo, la legislación urbanística de Andalucía, concretamente el Art. 9 apartado G de la Ley 7/2002, de 17 de diciembre, de Ordenación Urbanística de Andalucía que señala que una de las finalidades de los Planes Generales de Ordenación Urbana es la de: «Evitar procesos innecesarios de especialización de usos en los nuevos desarrollos urbanísticos de la ciudad». En este mismo sentido, el Art. 3.1 b) de esta misma Ley que se encarga de definir los fines de la actividad urbanística, señala que uno de esos fines es el de «Vincular los usos del suelo a la utilización racional y sostenible de los recursos naturales».

A pesar de que la técnica de la calificación urbanística hunda sus raíces en las primeras leyes que configuran el Derecho urbanístico moderno, en la actualidad, es una técnica que es puesta en cuestión desde diversos ámbitos. Así, por ejemplo, desde los órganos encargados de la defensa de la competencia se considera que la técnica de la zonificación o calificación conlleva una gran rigidez para el mercado del suelo y puede provocar distorsión a la hora de gestionar este recurso natural que es el suelo. Así, la Comisión Nacional de la Competencia emitió en 2011 un informe titulado Problemas de competencia en el mercado del suelo en España. En este informe, desde una perspectiva económica y regulatoria, se hace una crítica

\footnotetext{
7 Un análisis muy claro y detallado del régimen jurídico de los usos urbanísticos del suelo, véase, DE GUERRERO MANSO, C., La zonificación de la ciudad: concepto, dinámica y efectos. Ed. Aranzadi, 2012. Igualmente, puede verse el trabajo de ROMERO ALOY, M. J., "La zonificación urbanística. Algunas innovaciones", Práctica Urbanística, núm. 109, Sección Estudios, noviembre, 2011 , pág. 22. En palabras de esta última autora: «La zonificación es una técnica instrumental alumbrada desde el comienzo del urbanismo que cobra su plena definición con el movimiento racionalista expresada singularmente en la Carta de Atenas. Su aplicación es universal en cuanto que es una metodología básica para la redacción del plan urbanístico. Es una materia nacida en el seno de la praxis urbanística, recibida después por el derecho urbanístico, si bien, a pesar de su general aplicación, como materia "de frontera" adolece de una escasa atención por parte de la doctrina».

${ }^{8}$ Véase en este sentido el trabajo de YAÑEZ VELASCO, I., "Concepto de uso en la legislación del suelo (Especial referencia a la calificación y zonificación)", en Revista de Derecho Urbanístico y Medio Ambiente, núm. 156, septiembre-octubre, 1997, págs. 65 a 120. Este trabajo resulta muy interesante y crítico con la teoría de la zonificación proponiendo un sistema alternativo, si se quiere, de corte más liberal y menos intervencionista que el que tenemos asumido en el derecho urbanístico español desde su creación.

9 Por señalar el caso del municipio donde se escriben estas líneas y a título de ejemplo podemos citar el Plan General de Ordenación Urbana de Granada cuyo Título VI es el lugar elegido por el planificador urbano de esta ciudad para regular los usos del suelo en su término municipal estableciendo diferentes modalidades y criterios de clasificación. Concretamente, en el art. 6.1.2 se diferencia entre usos globales y usos pormenorizados. Por su parte, el art. 6.1.3 clasifica los usos en dominantes o característicos, compatibles o permitidos, complementarios y prohibidos.
} 
profunda a la técnica de la calificación y zonificación. Conforme a dicho informe ${ }^{10}$, en teoría, «la finalidad principal de la calificación es separar usos incompatibles para corregir externalidades. Por ejemplo, la industria genera externalidades como ruido, olor, humo, polvo o vibraciones; las zonas comerciales generan externalidades como congestión, conflictos de aparcamiento, ruido... Separando unos usos de otros, la calificación intenta evitar que tengan lugar esos efectos externos negativos entre usos incompatibles, que, sin lugar a dudas, existen y podrían generar una pérdida de bienestar». Pero, para este órgano estatal, la calificación genera otros problemas: "En suma, el sistema de calificación no constituye un mecanismo suficientemente eficaz para corregir determinadas externalidades, puede llevar a una provisión ineficiente de bienes públicos y limita de forma considerable la competencia en el mercado del suelo, afectando, de distinto modo, a la competencia en multitud de sectores económicos en los que el ámbito geográfico del mercado pueda tener nivel local. A su vez, del mismo modo que la frontera urbanística, su capacidad para conseguir corregir fallos de mercado se encuentra influida y distorsionada por los comportamientos de búsqueda de rentas y la dependencia de los Ayuntamientos de los ingresos provenientes del suelo y de la vivienda. Por último, tiende a limitar en cierto modo la aparición de zonas de uso mixto, lo que puede generar una mayor movilidad obligada, desplazamientos más largos y más contaminación, efectos contrarios a los que el propio planeamiento persigue».

Para la Comisión Nacional de la Competencia, denominación de aquél ente en el momento de redacción de este informe, un sistema alternativo podría ser el de la zonificación por estándares en vez de una zonificación basada en usos incompatibles. Con esta zonificación por estándares se podrían corregir las externalidades vinculadas a determinados usos, pero sin decidir ex ante la localización o la cantidad de suelo asignada a los distintos usos ${ }^{11}$. Así se provocaría un mayor grado de competencia en usos alternativos del suelo, una mayor flexibilidad en el uso del suelo y una mejor respuesta a las necesidades del mercado por parte de la oferta. En definitiva, habría que corregir una planificación tan intervencionista y que detalla los usos de forma tan pormenorizada, con la finalidad de no segmentar en exceso el mercado y favorecer más la competencia en la asignación del suelo.

\section{Del alojamiento colaborativo al alojamiento turístico o vacacional: el tránsito del uso residencial al uso terciario hotelero}

Los orígenes del alojamiento turístico o vacacional como actividad profesional que es en la actualidad, cabe encontrarlos en el llamado alojamiento colaborativo. Se trata, realmente, de una modalidad o manifestación de la conocida como economía colaborativa que se basa en operaciones o transacciones centradas enteramente en el intercambio o la cooperación y carentes de ánimo de lucro. En la actualidad, sin embargo, nos encontramos con la prestación de servicios o la cesión de bienes a cambio de una remuneración. En estos casos ni se participa ni se coopera, sino que simplemente se vende un bien o un servicio, es decir, se desarrolla una actividad profesional. Hablar de que estas plataformas virtuales promueven la economía colaborativa es un mero eufemismo que en demasiadas ocasiones no persigue sino justificar el incumplimiento de obligaciones legales que cualquier actividad de esta índole, como las equivalentes a las mismas, han de satisfacer en beneficio de ciertos valores públicos, desde las fiscales a las de orden público ${ }^{12}$.

10 Pág. 53 y siguientes. Haciéndose eco de este Informe y en términos muy parecidos, véase el Informe CDC PROM 14/2015 VIVIENDAS TURÍSTICAS de la Comisión de Defensa de la Competencia de la Generalitat Valenciana. En este Informe se proponen medidas alternativas a la calificación tal y como se entiende en la actualidad para el caso de las viviendas turística. Así, por ejemplo, se plantea como un buen mecanismo el de crear un mercado de derechos o la asignación de un porcentaje máximo de viviendas por barrios o zonas; además de seguir utilizando los impuestos o tasas de carácter turístico.

11 El Informe, pone el ejemplo de la calificación actual que tiende a separar grandes superficies de zonas residenciales, la calificación por estándares establece unos requisitos para que un centro comercial situado cerca de una zona residencial no genere externalidades sobre ésta. Para ello, puede exigirse que los centros comerciales tengan unos aparcamientos adecuados, establezcan la infraestructura necesaria para organizar de forma adecuada el tráfico extra generado, o se construyan de forma que se limite su impacto acústico y ambiental.

12 DE LA ENCARNACIÓN, M., "El alojamiento colaborativo: viviendas de uso turístico y plataformas virtuales", en Revista de Estudios de la Administración Local y Autonómica (REALA), núm. 5 (enero-junio, 2016), pág. 52. No obstante, aunque esta sea la regla general y para la que va destinada gran parte de la reglamentación pública, aún cabría diferenciar dos supuestos que no se están teniendo en cuenta con las medidas urbanísticas o de zonificación adoptadas por algunos de los municipios que se han decidido a intervenir en este ámbito: a) vivienda que se destina en su totalidad y en exclusiva al servicio turístico; b) casos en que la vivienda se destina a lo largo del año a dos usos, el de vivienda y el turístico. El propietario -o arrendatario- de una vivienda en la que reside habitualmente, la destina ocasionalmente (por completo o por partes) al uso turístico (alojamiento de turistas). En este sentido, ATXUKARRO ARRUBARRENA, I., "La regulación urbanística de las viviendas para uso turístico", en El Consultor de los Ayuntamientos, núm. 12 (2017). 
El tránsito de una actividad sin ánimo de lucro a constituir una actividad profesional y, por tanto, remunerada, tiene su correlato en los usos urbanísticos. Mientras que las viviendas, lógicamente, han sido construidas en la medida en que el correspondiente planeamiento urbanístico ha previsto en ese suelo el uso residencial (en sus diferentes modalidades), en el momento en que esa vivienda no se destina al uso residencial «tradicional» se viene exigiendo tanto por los Ayuntamientos como por las Comunidades Autónomas que estas viviendas se encuentren en suelos con uso terciario. El uso terciario es aquél que tiene por finalidad la prestación de servicios al público, las empresas u organismos, tales como los servicios de alojamiento temporal, comercio al pormenor en sus distintas formas, información, administración, gestión, actividades de intermediación financiera u otras similares.

La frontera o el elemento distintivo entre una vivienda dedicada a residencia tradicional y una vivienda turística no está clara. El elemento que más claramente trata de diferenciar uno y otro tipo es la temporalidad tal y como, por ejemplo, ha señalado la Sentencia del Tribunal Superior de Justicia de Madrid de 17 de abril de 2013 ${ }^{13}$ : el residencial se caracteriza por la estabilidad y permanencia y el uso turístico se caracteriza por la transitoriedad y ocasionalidad (por días), por eso es un uso terciario.

Aquí nos encontramos ya con una primera dificultad de carácter urbanístico. ¿Se requiere una licencia urbanística por cambio de uso cuando una vivienda ha dejado de tener carácter residencial y ha pasado a tener carácter terciario-turístico? La jurisprudencia dictada hasta la fecha mantiene posiciones encontradas. La Sentencia del Tribunal Superior de Justicia (TSJ) de Madrid de 17 de abril de $2013^{14}$ y la del Juzgado de lo Contencioso Administrativo núm. 1 de San Sebastián, de 5 de diciembre de $2016^{15}$, consideran que sí ya que estaríamos ante un uso terciario-hotelero y, por tanto, requiere licencia de cambio de uso. Sin embargo, la Sentencia de 27 de abril de 2016 del Juzgado núm. 6 de lo Contencioso-administrativo de Valencia ${ }^{16}$ sostiene que no hay cambio de uso ya que el uso sigue siendo de vivienda.

Dado el carácter local de las medida urbanísticas, la solución al problema del tránsito de un tipo a otro de vivienda no puede ser general. Cada Ayuntamiento está interpretando la necesidad o no de licencia por cambio de uso como está considerando situación que, entre otras, hace plantearse la necesidad o no de una regulación general y homogénea de esta herramienta urbanística.

\section{El indeterminado y heterogéneo régimen jurídico de la zonificación o calificación urbanística}

El camino emprendido por muchos municipios españoles, en el caso de los alojamientos turísticos, parece ir en sentido contrario a la diversidad y mezcla de usos para construir ciudades urbanísticamente más ricas y flexibles. Para evitar los, a vistas de algunos, efectos perjudiciales de la excesiva proliferación de alojamientos turísticos en el centro de las ciudades, se decide "zonificar» la ciudad con la intención de ubicar en determinadas partes de la ciudad los usos turísticos ofrecidos por canales diferentes a los tradicionales usos hoteleros. En otras ocasiones, directamente, se pretende la prohibición en todo un municipio de este tipo de alojamientos. La variedad y riqueza que proporciona el modelo heterogéneo de usos del suelo en la ciudad se olvida en el caso de los nuevos alojamientos turísticos.

El exceso de turismo en el centro de las ciudades, la subida de precios de las viviendas destinadas a uso residencial principal, molestias a los vecinos, etc., son algunas de las razones que se esgrimen por los Ayuntamientos para tomar este tipo de decisiones. Por otra parte, las asociaciones encargadas de defender los intereses de este nuevo mercado, además del excesivo y, en algunas ocasiones, arbitrario intervencionismo local, ven al lobby hotelero tradicional detrás de este tipo de decisiones en una actuación similar a la que lleva a cabo la gremial del taxi frente a plataformas de transporte como Blablacar, Uber o Cabify ${ }^{17}$.

El problema que se plantea es que, salvo determinadas excepciones autonómicas, la regulación de la zonificación o calificación urbanística en normas territoriales y urbanísticas de carácter general es muy escasa y se deja, prácticamente, total libertad a los municipios para adoptar a nivel reglamentario medidas

13 RJCA 20131680

14 RJCA 20131680

15 JURI2017\287138.

16 JURI2016\102384.

17 El día 4 de junio de 2018 (en el momento de redacción de estas páginas no está disponible la Sentencia aún en los repertorios jurisprudenciales al uso) se ha dado a conocer públicamente la Sentencia del Tribunal Supremo que avala las limitaciones que el anterior Gobierno impuso por Real Decreto en noviembre de 2015 a la expansión de las empresas de vehículo de alquiler con conductor (VTC), las firmas como Uber y Cabify, al considerar que se trata de una medida «idónea y proporcionada» para asegurar «el mantenimiento del taxi como un servicio de interés general». 
REALA. Nueva Época - N. ${ }^{10}$, Octubre 2018 - ISSN: 1989-8975 - DOI: 10.24965/reala.v0i10.10545 - [Págs. 6-21]

La intervención local en las viviendas de uso turístico a través de la zonificación urbanística: requisitos y consecuencias

Estanislao Arana García

que pueden afectar a derechos fundamentales como la propiedad o libertades fundamentales como la de empresa o la de prestación de servicios.

Salvo la referencia genérica citada con anterioridad a la técnica clasificatoria y calificatoria contenida en las leyes estatales del suelo y algunas determinaciones también muy vagas en las leyes autonómicas de urbanismo, la regulación de la zonificación urbanística es realmente escasa. El todavía vigente Reglamento de Planeamiento Urbanístico de $1978^{18}$, señala en su artículo 25.1. que «Los elementos fundamentales de la estructura general y orgánica de la ordenación del territorio se establecerán por el Plan General teniendo en cuenta el modelo de desarrollo urbano adoptado, definiendo: a) La asignación a las diferentes zonas de los correspondientes usos globales cuya implantación se prevea, y la intensidad de los mismos». Por su parte, el Art. 29.1 indica que: «En suelo urbano, los Planes Generales contendrán, además de las determinaciones de carácter general, las siguientes: c) Asignación de usos pormenorizados correspondientes a las diferentes zonas, definiendo de forma detallada la específica utilización de los terrenos incluidos en cada una de ellas».

Algunas Comunidades Autónomas, las menos, han regulado con cierto detalle esta técnica o herramienta de la zonificación. En este sentido, especialmente, destaca la Comunidad Valenciana que aprobó un Reglamento de zonificación (Orden de 26 de abril de 1999, del Conseller de Obras Públicas, Urbanismo y Transportes por la que se aprueba el Reglamento de Zonas de Ordenación Urbanística de la Comunidad Valenciana). En menor medida, la Comunidad de Castilla-La Mancha, con la promulgación del Decreto 248/2004, de 14 de septiembre por el que se aprueba el Reglamento de Planeamiento de la Ley de Ordenación del Territorio y de la Actividad Urbanística, también regula la zonificación con cierto detalle. Finalmente, el Decreto 278/2007, por el que se aprueba el Reglamento de Ordenación del Territorio y Urbanismo del Principado de Asturias, contiene también elementos innovadores, si bien no acomete de modo directo una regulación de la zonificación.

Aunque el ámbito de la planificación urbanística es uno de los paradigmas o manifestaciones más claras de la autonomía local, dejar absolutamente a cada municipio de este país libertad absoluta para decidir respecto a los tipos de usos e intensidades del suelo genera, como está generando, numerosos problemas ${ }^{19}$. El Preámbulo del Reglamento de Zonificación de la Comunidad Valenciana expresa lo que se pretende conseguir con una regulación general y objetiva de esta herramienta: «Por el contrario, la sistematización, la estandarización y la búsqueda de un lenguaje común, genera transparencia y homogeneidad, respetando siempre, la idiosincrasia y la autonomía municipal. Con todo ello el Reglamento de Zonas de Ordenación Urbanística dotará de una mayor capacidad simplificadora y clarificadora a los planes, haciéndolos más accesibles, tanto para los técnicos como para los ciudadanos».

Es cierto que las necesidades de cada municipio pueden ser diferentes y que la incidencia de las llamadas viviendas turísticas es diverso ${ }^{20}$. No podemos rechazar de plano la posibilidad de que los municipios hagan ejercicio de su autonomía para decidir en este ámbito. Sin embargo, las decisiones locales que se

18 Real Decreto 2159/1978, de 23 de junio, por el que se aprueba el Reglamento de Planeamiento para el desarrollo y aplicación de la Ley sobre Régimen del Suelo y Ordenación Urbana.

${ }^{19}$ En este sentido se pronuncia ROMERO ALOY, M. J., "La zonificación urbanística ...”, cit. anteriormente: «No parece que sea lo más conveniente que cada plan invente su propio lenguaje y defina lo que deba entenderse por cada uno de los numerosos parámetros urbanísticos que intervienen en la ordenación, tales como parcela edificable, bloque adosado, altura reguladora, profundidad edificable, uso terciario, etc. Parece más razonable la existencia de un patrón de referencia común».

20 El Diario Expansión de 30 de abril de 2018 ha publicado un artículo en el que hace un análisis de la regulación de las viviendas turísticas ciudad por ciudad. En Barcelona se ha optado por medidas drásticas para controlar el aumento desenfrenado de pisos turísticos. Desde 2017 su Plan Urbanístico establece una moratoria que afecta tanto a hoteles como a pisos turísticos y que divide la ciudad en 4 zonas, en función de si se puede aumentar o no el número de plazas. También reforzó los inspectores y las sanciones. San Sebastián dió luz verde a su ordenanza municipal en enero de este año. Su objetivo es limitar los pisos al 15\%, aunque su plan pasa por la zonificación, creando tres zonas: una, en el centro, donde queda prohibido el alquiler turístico; otra que permite la ocupación parcial y una última que autoriza dos viviendas en plantas altas. Eso sí, sólo en edificios de a partir de 7 pisos. En Madrid, aunque la capital todavía no cuenta con su Plan de pisos turísticos, Carmena anunció que quien quiera alquilar un piso turístico sin licencia no podrá sobrepasar los 90 días. A partir del cuarto mes, tendrá que pedir una licencia de uso comercial, como un restaurante o un bar. Mientras elabora el plan, el Ayuntamiento suspenderá la concesión de licencias en el centro durante un año. Palma de Mallorca amenaza con convertirse en la primera ciudad española en prohibir el alquiler turístico. El ayuntamiento, gobernado por PSOE, Podemos y MES, anunció que a partir de julio la ciudad será considerada 'zona única', donde no se podrá alquilar pisos turísticos. La ley excluye viviendas unifamiliares al considerar que no causa problemas de convivencia. Valencia quiere limitar el alquiler vacacional sin licencia, pero tiene dudas sobre dónde poner el coto. Siguiendo la estela de Madrid, el Ayuntamiento valenciano plantea un límite de entre uno y tres meses. Quien no llegue al máximo no necesitará ceñirse a la normativa de uso profesional. El consistorio tampoco descarta la 'zonificación'. Bilbao, desde hace muy poco, comenzó a poner límites a las plataformas de alquiler turístico. Aunque por el momento no cuenta con una normativa en vigor al respecto, Bilbao plantea crear la figura legal de los pisos turísticos - que no tenía- para poder recaudar impuestos. Además, sólo podrá haber un alojamiento de este tipo por portal, y sólo en el primer piso. 
adopten en este sentido tienen que encontrar una adecuada acomodación constitucional y, sobre todo, van a estar necesitadas de una motivación muy intensa en la medida en que se trata de medidas restrictivas para determinados derechos fundamentales. Mientras que decisiones autonómicas limitadoras de este tipo de alojamientos turísticos son muy discutibles desde un punto de vista constitucional pero, al menos, han sido adoptadas mediante normas con rango de ley, muchas de estas restricciones están siendo adoptadas de forma mucho más opaca mediante simples medidas urbanísticas que no gozan de las mismas exigencias de transparencia y garantías que cabe predicar de las normas que emanan de los diferentes parlamentos. A sensu contrario, a favor de las garantías de los particulares, este tipo de decisiones administrativas tienen un más fácil acceso a la jurisdicción contencioso-administrativa que si se pretendiera tratar de enjuiciar medidas de rango legal autonómico cuya revisión sólo al Tribunal Constitucional corresponde con las consabidas limitaciones de legitimación para poder solicitar un pronunciamiento del Alto intérprete constitucional.

La heterogeneidad y falta de criterios generales sobre el uso de la técnica de la zonificación puede dar lugar a situaciones realmente extrañas como la que tiene lugar en determinados municipios en los que su planeamiento urbanístico contempla usos turísticos y que, sin embargo, prohíben la utilización en estos suelos de los llamados alojamientos turísticos, esto es, de viviendas que puedan ser utilizadas para servicios turísticos pero que son ofrecidos al margen de los sistemas hoteleros tradicionales haciéndolo a través de plataformas digitales como Arbnb. Es el caso de Canarias, por ejemplo ${ }^{21}$. Es un caso extremo y que resulta difícil, a priori, de justificar y entender.

\section{La zonificación o calificación urbanística es un requisito para el ejercicio de una actividad económica y, por tanto, en función de las circunstancias, podría considerarse una medida contraria a la libertad de prestación de servicios pero no de forma automática}

Una de las cuestiones más importantes que se plantea respecto a la zonificación como técnica regulatoria y de control del alojamiento turístico es si ésta se puede considerar una medida que limita la libertad de prestación de servicios como libertad fundamental en la Unión Europea y, por tanto, podría considerarse contraria a la Directiva 123/2006, de 12 diciembre, de Servicios. Evidentemente, aunque estemos ante una medida regulatoria de carácter urbanístico y no de la actividad turística en sí, las decisiones que se adopten en el ámbito urbanístico condicionan definitivamente la propia actividad. Contamos ya con varios pronunciamientos judiciales que han tratado este tema y que han tratado de aclarar la situación.

En primer lugar, quisiera referirme a una Sentencia reciente del Tribunal de Justicia de la Unión Europea (Gran Sala) de 30 de enero de $2018^{22}$. En este asunto se analizaba, además de otras cuestiones que ahora no nos interesan, la compatibilidad con el Derecho de la Unión de una medida urbanística de un Ayuntamiento de Países Bajos (Appingedam) consistente en prohibir que el comercio minorista de zapato y calzado se ubicara fuera del centro de la ciudad. La Sentencia se dicta como consecuencia de una cuestión prejudicial planteada por el Consejo de Estado de los Países Bajos. Para la empresa recurrente, el plan urbanístico infringe los artículos 9 y 10 de la Directiva de Servicios. Por su parte, el Ayuntamiento defendía que consideraciones de ordenación del territorio justifican que un comercio minorista de ropa y calzado sólo pueda instalarse en el centro de la ciudad. Señala que esta norma pretende mantener la habitabilidad del centro de la ciudad, garantizar el buen funcionamiento del centro comercial que se encuentra en ella y evitar en la mayor medida posible la desocupación estructural de locales en el centro de la ciudad. Como puede verse, se trata de un caso realmente asimilable al problema que estamos analizando y muchas de las consideraciones que realiza el Tribunal pueden ser extrapolables al caso de las viviendas turísticas.

En primer lugar, el Tribunal de Justicia considera que la actividad de comercio minorista de productos como ropa y calzado está comprendida en el concepto de «servicio» en el sentido del artículo 4, punto 1, de la citada Directiva de Servicios. Tras descartar que estas medidas de zonificación quepa considerarlas como

21 SIMANCAS CRUZ, M. R., PEÑARRUBIA ZARAGOZA, M. P., y TERMES, R.: "La calificación urbanística del suelo: cuestión clave en la prohibición del alquiler vacacional en las áreas turísticas de litoral de Canarias", en Cuadernos geográficos de la Universidad de Granada, vol. 57, núm. 1, 2018, págs. 177-196.

22 Caso College van Burgemeester en Wethouders van de gemeente Amersfoort y Otros contra Visser Vastgoed Beleggingen BV y Otros. (TJCEI2018117). Un antecedente de este caso puede encontrarse en la Sentencia del propio Tribunal de Justicia de la Unión Europea de 29 de abril de 1999 (C-302/97), Konle, que señala, entre otras cosas, que «un objetivo de ordenación del territorio como el mantenimiento, en interés general, de una población permanente y una actividad económica autónoma respecto del sector turístico en ciertas regiones, la medida restrictiva que constituye dicha exigencia sólo puede admitirse si no se aplica de forma discriminatoria y si otros procedimientos menos coercitivos no permiten llegar al mismo resultado». 
REALA. Nueva Época - N. ${ }^{10}$, Octubre 2018 - ISSN: 1989-8975 - DOI: 10.24965/reala.v0i10.10545 - [Págs. 6-21]

La intervención local en las viviendas de uso turístico a través de la zonificación urbanística: requisitos y consecuencias

Estanislao Arana García

autorización administrativa a los efectos de la Directiva, sin embargo, sí considera que se trata de uno de los requisitos a que se refiere el artículo 15, apartado 2 de la Directiva puesto que supedita el acceso a una actividad de servicios o su ejercicio a un límite territorial en el sentido del artículo 15, apartado 2, letra a), de dicha Directiva. Sin embargo, a pesar de ser una medida que, en principio, obligaría a los Estados miembros a ser revisadas en la medida en que pudiera ser contraria a la libre prestación de servicios, las mismas no se consideran prohibidas de forma directa y automática. Por el contrario, si este tipo de medidas cumplen con los requisitos del apartado 3 de dicho precepto, podrían considerarse compatibles.

La Directiva 2006/123 no se opone a que el acceso a una actividad de servicios o su ejercicio se supedite al respeto de un límite territorial de esta índole, siempre que se cumplan las condiciones de no discriminación, necesidad y proporcionalidad enunciadas en su artículo 15, apartado 3.

Respecto a la condición de necesidad, el Tribunal, siguiendo la opinión del Abogado General, en este caso, considera que el intento de preservar la habitabilidad del centro de la ciudad del municipio de Appingedam y evitar la existencia de locales desocupados en zona urbana en interés de una buena ordenación del territorio puede ser considerada como una razón imperiosa de interés general que (Art. 4.8 de la Directiva) que justifique un límite territorial como el controvertido en el litigio principal.

En definitiva, se trata de una competencia de los Estados y, por tanto, de los Tribunales nacionales, concretar caso a caso que una medida de este tipo cumple con los requisitos de: a) no discriminación: que los requisitos no sean discriminatorios, ni directa ni indirectamente, en función de la nacionalidad o, por lo que se refiere a las sociedades, del domicilio social; b) necesidad: que los requisitos estén justificados por una razón imperiosa de interés general; c) proporcionalidad: que los requisitos sean adecuados para garantizar la realización del objetivo que se persigue y no vayan más allá de lo necesario para conseguir dicho objetivo y que no se puedan sustituir por otras medidas menos restrictivas que permitan obtener el mismo resultado.

Esta es, entendemos, hasta la fecha la interpretación que ha realizado el Tribunal de Justicia de la Unión Europea y que, probablemente, vayan a seguir los Tribunales y Juzgados de nuestro país cuando se plantee esta cuestión respecto a zonificaciones que tengan que ver con los alojamientos turísticos. No hay argumentos absolutos y hay que analizar caso a caso para poder afirmar que una determinada decisión local respecto a la localización de las viviendas turísticas es o no conforme al Derecho de la Unión Europea y, consecuentemente, conforme al Ordenamiento Jurídico aplicable. Habrá que analizar con profundidad la motivación técnica que esgrime el Ayuntamiento correspondiente para ver si salva los requisitos mencionados con anterioridad y todo ello porque, como ha afirmado el Tribunal Europeo, las medidas urbanísticas y territoriales pueden considerarse razones imperiosas de interés general justificadoras de medidas restrictivas en cuanto a la ubicación de este tipo de alojamientos.

En el ámbito estrictamente nacional, se han planteado supuestos parecidos, ya sea directamente en casos que afectan a las viviendas turísticas ya sea referidos a otro tipo de actividades que también son objeto de limitaciones vía zonificación. Como seguidamente vamos a ver con más detalle, en aquellos lugares donde se ha planteado este conflicto, los Tribunales de Justicia han entendido que estamos ante el ejercicio de una verdadera competencia urbanística y que, por tanto, los Ayuntamientos que han decidido intervenir en este sector no están invadiendo las competencias autonómicas en materia de turismo. Ello siempre y cuando la zonificación o utilización de la calificación urbanística para ubicar el uso turístico residencial en una determinada parte de la ciudad no se lleve a cabo globalmente (por ejemplo, en un Plan General de Ordenación Urbana) sino con planes especiales por ejemplo, que sólo afectan a una parte de la ciudad. En caso contrario se estaría produciendo una regulación general que sólo se permite al Plan General de Ordenación Urbana y que requeriría, entre otras cosas, el visto bueno de la Comunidad Autónoma por ser la competente en materia de turismo ${ }^{23}$. Además, por supuesto, de poder ser considera más claramente como una medida desproporcionada.

Merece la pena traer aquí el conflicto jurídico que tuvo lugar en la ciudad de Barcelona con motivo del Plan especial de establecimientos de concurrencia pública, hotelería y otras actividades en Ciutat Vella de 2010. Tanto su versión original de 2010 como su versión modificada en 2013 han sido objeto de impugnaciones en vía judicial y han dado lugar a dos pronunciamientos por parte del Tribunal Superior de Justicia de Cataluña muy interesantes y que centran la discusión que se está produciendo en la actualidad en otras ciudades del país. Las Sentencias a que me refiero son las del Tribunal Superior de Justicia de Cataluña de

${ }^{23}$ En este sentido se ha pronunciado el Tribunal Supremo en su Sentencia de 27 de julio de 2010 (Rec. 4069/2006). RJI201016550. 
REALA. Nueva Época - N. ${ }^{10}$, Octubre 2018 - ISSN: 1989-8975 - DOI: 10.24965/reala.v0i10.10545 - [Págs. 6-21]

La intervención local en las viviendas de uso turístico a través de la zonificación urbanística: requisitos y consecuencias

Estanislao Arana García

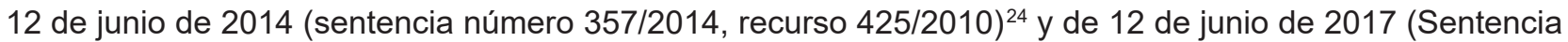
número 371/2017, recurso 254/2013) ${ }^{25}$.

Muy resumidamente, el Plan Especial de Ciutat Vella pretende redistribuir los usos urbanísticos en parte del municipio de Barcelona, concretamente, en una zona donde según los redactores del instrumento urbanístico se da un exceso de infraestructura turística que está provocando una degradación de la vida ciudadana ordinaria y un evidente perjuicio al medio ambiente urbano. Fundamentalmente, el objeto de regulación del Plan especial se produce en relación al uso hotelero y a las viviendas o residencias turísticas. En relación a los usos hoteleros, lo que se pretende, en definitiva, es limitar la posibilidad de autorizar nuevas plazas hoteleras en algunas partes de la ciudad condal. Conforme a la modificación de 2013: «El espíritu que enmarca las determinaciones del Plan de usos 2010 en relación con las actividades hoteleras es muy claro: no se puede aumentar el número de plazas en un distrito donde la oferta existente es muy superior a la media de los otros distritos barceloneses y pone en peligro el equilibrio entre las necesidades de la población residente y la población flotante. Es por eso que su regulación es muy estricta. Sólo se permite la implantación de nuevas plazas hoteleras (ya sean ampliación de establecimientos existentes o bien de nueva creación) en las ZE-1, 5 y 11 siempre que se renuncie a otras plazas existentes. Se bloquea de esta manera el número total de plazas existentes en el distrito y simplemente se permite su relocalización, facilitando así la renovación y modernización de los establecimientos (...)».

Frente a este argumento como fundamento del Plan Especial, los recurrentes entienden que se vulneran las libertades fundamentales de la Unión Europea de libre prestación de servicios y de establecimiento y su desarrollo, en parte, por la Directiva de Servicios de 2006, en cuanto que se da un trato discriminatorio al prestador de servicios al impedir «de facto» la implantación de un nuevo establecimiento en esa zona específica sin que exista ninguna razón imperiosa de interés general que lo impida, y siendo posible la adopción de medidas menos restrictivas, como sería limitar el número de camas de cada establecimiento hotelero, su categoría o implantar un régimen de distancias, tal y como se hace con el resto de actividades de restauración y otros comercios. Por otra parte, se entiende que también se vulneran los Derechos fundamentales a la libertad de empresa y a la igualdad reconocidos respectivamente en los artículos 38 y 14 de la Constitución Española de 1978. En definitiva, como señalaba al principio de este trabajo, el conflicto tiene que ver al enfrentarse dos tipos de Derechos, los colectivos al medio ambiente urbano y los individuales de igualdad y libertad en su sentido o extensión económica.

Ninguna de estas alegaciones va a ser acogida por el Tribunal Superior de Justicia de Cataluña. En primer lugar, respecto a la hipotética vulneración de la libertad europea de prestación de servicios, porque entiende que la raíz de las decisiones adoptadas por el Plan Especial tienen carácter urbanístico, no están regulando ni limitando la actividad turística y, por tanto, no les resulta de aplicación la Directiva de Servicios ya que el urbanismo es una de las razones de imperioso interés general que permite su excepción. Se trata, en palabras de la sentencia de 2017 mencionada, de regular ciertas condiciones previas o colaterales al establecimiento de un servicio, tratando de evitar su excesiva y urbanísticamente nociva proliferación, del mismo modo que el planeamiento regula otros elementos por la vía de la fijación de estándares u otros procedimientos. Es decir, el plan especial regula la implantación urbanística de los hoteles y restantes establecimientos a que se refiere, pero no la actividad en ellos a desarrollar en su sentido estricto ni sus condiciones de funcionamiento posterior.

El Tribunal Superior, por tanto, acoge, en parte la doctrina del Tribunal de Justicia de la Unión Europea aunque realiza una consideración que dista bastante de la resolución del Tribunal Europeo. En concreto, para el Tribunal Superior de Justicia de Cataluña, el mero hecho de tratarse de una medida de carácter urbanístico excluye la aplicación de la Directiva de Servicios. Sin embargo, como ya hemos visto, para el Tribunal de Justicia de la Unión Europea, aún tratándose de una medida urbanística, se condiciona absolutamente el ejercicio de una actividad turística y, por tanto, puede ser objeto de control bajo el paraguas y condicionantes de la Directiva de 2006.

Tampoco se considera que se vulneren los Derechos fundamentales de libertad de empresa e igualdad en la medida en que la Jurisprudencia del Tribunal Constitucional ha considerado que estos derechos no son ilimitados y que, si se justifica adecuadamente, pueden ser objeto de limitaciones y regulaciones sin que se vea afectado su contenido esencial.

\footnotetext{
24 JURI2017\178345.

25 RJCAl20171829.
} 
Por lo que a las viviendas turísticas expresamente se refiere, el mencionado Plan Especial también establece importantes limitaciones en la medida en que no se otorgarán nuevas licencias de este tipo a no ser que se produzca una baja de las anteriormente concedidas y, adicionalmente, se prohíbe este tipo de alojamientos en edificios que tengan como destino el residencial habitual. En definitiva, sólo se va a permitir este tipo de alojamientos, en la zona afectada por el Plan Especial, en aquellos edificios dedicados exclusivamente a residencial turístico.

Pues bien, el Tribunal Superior de Justicia de Cataluña extiende los argumentos empleados para el enjuiciamiento de las medidas referidas al uso hotelero a las limitaciones introducidas en el Plan Especial enjuiciado a las viviendas turísticas. Al margen de otros pronunciamientos interesantes que se realizan en las dos Sentencias que estoy comentando, a los efectos de este trabajo, la consideración más interesante que realiza tiene que ver con el carácter urbanístico o turístico de la prohibición de este tipo de viviendas en edificios que cuenten con viviendas destinadas al uso residencial habitual. En este sentido, coherentemente con lo señalado respecto a la aplicabilidad o no de la Directiva de Servicios a este tipo de conflictos, la Sentencia de 2017 afirma que se trata de una medida de carácter urbanístico, competencia, por tanto, de la Administración local y no de la autonómica y que, consecuentemente, con la debida motivación es susceptible de acordarse por parte de los Ayuntamientos de este país.

En definitiva, conforme a esta interpretación judicial, las medidas adoptadas por los Ayuntamientos regulando y ubicando las viviendas destinadas a alojamientos turísticos en determinadas partes de la ciudad tienen carácter urbanístico y, por tanto, están exentas de la aplicación de los principios propios de las libertades económicas de establecimiento o de empresa. Siempre que las Administraciones locales utilicen sus competencias urbanísticas con la suficiente y completa motivación, las restricciones al alojamiento turístico que puedan introducir se consideran posibles. Con esta importante matización referida a la motivación de la decisión, la doctrina del Tribunal Superior se aproxima más a la del Tribunal de Justicia de la Unión Europea.

El caso del Plan Especial de Ciutat Vella es muy concreto y sus consideraciones no se pueden extender sin más a cualquier situación o supuesto. En este caso, el Ayuntamiento de Barcelona presentó una serie de estudios y análisis que demostraban que los usos turísticos en determinadas zonas de la ciudad de BarceIona estaban generando realmente desequilibrios y daños al medio ambiente urbano que debían ser objeto de control y limitación. Sin embargo, una limitación generalizada y sin la suficiente motivación de este tipo de actividad económica (como la que se está ya anunciando en algunos municipios de este país), sin lugar a dudas, podría considerarse contraria a Derecho.

Este entendimiento del urbanismo y su técnica de la zonificación o calificación urbanística como justificación a limitaciones a actividades de carácter profesional en el ámbito del turismo, se ha aplicado igualmente y más recientemente por parte de otro Tribunal Superior de Justicia, en este caso el del País Vasco, para justificar medidas de zonificación respecto a otro tradicional uso terciario, en este caso, el de hostelería con medidas restrictivas para la instalación de este tipo de servicios en el Casco Histórico de Bilbao.

La Sentencia del Tribunal Superior de Justicia del País Vasco de 29 de enero de $2018^{26}$ analiza la legalidad de la modificación del Plan Especial de Rehabilitación del Casco Viejo de Bilbao, consistente en establecer un nuevo régimen de algunos usos urbanísticos para diferentes actividades (hostelería, seguros....) mediante el establecimiento de una nueva zonificación y, en definitiva, del establecimiento de un régimen de distancias mínimas entre las diferentes actividades a que se refiere. El recurso se interpone a instancia de la Autoridad Vasca de la Competencia.

Resumidamente, para la Autoridad Vasca de la Competencia, las medidas adoptadas por el Ayuntamiento Vasco suponen una restricción injustificada a la competencia por cuanto que se vulneran las libertades de establecimiento y libre prestación de servicios de los Arts. 49 y 56 del Tratado de Funcionamiento de la Unión Europea, de la Directiva 2006/123/CE, relativa a los servicios en el mercado interior y de los Arts. 33 y 38 de la Constitución Española y Art. 5 de la Ley 17/2009, de 23 de noviembre, sobre libre acceso a las actividades y su ejercicio.

Por parte de la Autoridad de la competencia se entiende que esta decisión se basa en razones puramente económicas y de defensa de un determinado tipo de comercio, el minorista tradicional frente al más pujante en estos momentos en aquella ciudad de hostelería. Para los recurrentes, se trata de una decisión administrativa falta de suficiente motivación y que constituye una limitación desproporcionada del derecho

26 RJCAI2018\13. 
REALA. Nueva Época - N. ${ }^{10}$, Octubre 2018 - ISSN: 1989-8975 - DOI: 10.24965/reala.v0i10.10545 - [Págs. 6-21]

La intervención local en las viviendas de uso turístico a través de la zonificación urbanística: requisitos y consecuencias

Estanislao Arana García

de propiedad de los propietarios de los locales comerciales del Casco Histórico de Bilbao que ven limitadas las posibilidades de desarrollar una actividad que hasta la fecha podrían realizar sin este tipo de limitaciones.

Por su parte, el Ayuntamiento de Bilbao considera que se trata de medidas o limitaciones perfectamente posibles, basadas en sus competencias urbanísticas y que están justificadas en razones imperiosas de interés general tales como la defensa del patrimonio cultural de Bilbao, la defensa del medio ambiente urbano, la salud y seguridad pública. Se entiende que la invasión del entorno del Casco Viejo por el uso hostelero estaba provocando daños en la convivencia vecinal y que, por tanto, la defensa del interés público exigía adoptar esta decisión.

Finalmente, el Tribunal Superior de Justicia del País Vasco y de conformidad con la doctrina del Tribunal de Justicia de la Unión Europea, considera que por lo que a las limitaciones del uso hostelero respecta, se trata de medidas no discriminatorias, que están justificadas en razones imperiosas de interés general, que son adecuadas para garantizar el objetivo que persiguen y que no van más allá de lo necesario. El Tribunal acepta el riguroso estudio aportado por el Ayuntamiento de Bilbao en el que, de forma numérica, se realiza un análisis de los diferentes locales y actividades abiertos y cerrados en los últimos años en cada parte de la ciudad, para concluir que la actividad de hostelería está creciendo de forma desproporcionada respecto al resto de actividades o usos de carácter terciario y que, por tanto, las limitaciones establecidas en el plan están justificadas.

Sin embargo, el Tribunal, no considera trasladables estas consideraciones respecto al uso hostelero a otras actividades como entidades de crédito y seguros, entidades de juego y recreativas y comercios de alimentación en régimen de autoservicio. La Sala no encuentra justificación que cumpla las exigencias legales anteriormente mencionadas (no discriminación, razones imperiosas de interés general, proporcionalidad y no existencia de otras medidas menos gravosas) que justifique la legalidad de las medidas restrictivas para este tipo de servicios diferentes a los hosteleros. Se trata, más bien, de justificaciones económicas prohibidas tanto por el Derecho de la Unión como por el Derecho estrictamente español.

En definitiva, al igual que sucedió en el caso de Ciutat Vella de Barcelona, el Tribunal Superior de Justicia del País Vasco considera posible que por la vía del ejercicio de competencias urbanísticas, el Ayuntamiento de Bilbao pueda limitar el ejercicio de determinadas actividades de servicios, en este caso las de hostelería, mediante la zonificación de determinadas partes de la ciudad. Establecimiento de zonas adecuadas para estas actividades o la fijación de cupos en cuanto al número de licencias que como máximo se pueden conceder en un determinado municipio para el desempeño de una concreta actividad, son medidas que, a juicio de los tribunales, perfectamente se pueden adoptar desde los ayuntamientos. Pero, en cualquier caso, lo que se considera imprescindible, como en cualquier potestad discrecional, es que esta decisión venga avalada por una completa motivación que justifique el porqué de estas medidas limitadoras del ejercicio de derechos económicos tan importantes como la libertad de establecimiento o la libertad de empresa. En los dos casos analizados, Barcelona y Bilbao, el Ayuntamiento ha decidido zonificar las actividades tras la aportación de análisis cuantitativos y cualitativos que acreditan la saturación de determinadas actividades (hotelera, viviendas turísticas o locales dedicados a la hostelería) en concretas partes de la ciudad.

Estamos en este caso en una aplicación más rigurosa si cabe de la doctrina del Tribunal de Justicia de la Unión Europea en la medida en que un mismo caso, en función de las circunstancias de cada uno de los usos urbanísticos y de las pruebas aportadas por la Administración, el Tribunal considera que los requisitos de necesidad, no discriminación y proporcionalidad en un caso se respetan y en otro no. No cabe, insistimos, una solución única y general, el análisis del cumplimiento de los criterios de legalidad de la Directiva de Servicios deben ser analizados caso a caso y en función de las concretas circunstancias del momento.

\section{Los cambios de uso de residencial a turístico y la necesidad de aumento de las dotaciones e infraestructuras}

Otro de los problemas que se puede plantear con la zonificación que están llevando a cabo determinados Ayuntamientos de nuestro país consistente en reubicar a las viviendas turísticas en determinadas zonas de la ciudad donde con anterioridad sólo cabía el uso residencial, es la necesidad de incrementar el número o porcentaje de dotaciones en esa parte de la ciudad donde ahora se permite un uso turístico que, probablemente, generará un aumento de la densidad edificatoria en esa zona urbana. Es una de las tradicionales consecuencias del ius variandi del planeamiento urbanístico.

Tradicionalmente, las diferentes leyes estatales del suelo han contemplado esta situación. Tanto el Art. 49.2 del Texto Refundido de la Ley sobre el Régimen del Suelo y Ordenación Urbana, aprobado por el 
Real Decreto Legislativo 1346/1976, de 9 de abril (TRLS76), como el artículo 128.2 de la Ley del Suelo de 1992, Texto Refundido aprobado por Real Decreto Legislativo 1/1992, de 26 de junio, (TRLS92), imponían la dotación de mayores espacios libres cuando la modificación del plan aprobada suponga el aumento de volumen de la zona ${ }^{27}$. En la legislación estatal actual, esta situación se denomina «actuaciones de dotación» y se regula en los artículos $7.1 \mathrm{~b})^{28}$ y en el 18 , respecto a los deberes de los propietarios afectados por estas actuaciones urbanizadoras ${ }^{29}$.

En el caso de la legislación urbanística autonómica, por ejemplo, el Art. 45 de la Ley 7/2002, de Ordenación Urbanística de Andalucía (LOUA), de 17 de diciembre, va más allá llegando incluso a considerar la posibilidad de que un suelo urbano consolidado pueda pasar a tener la condición de no consolidado por un cambio de uso en el planeamiento. Concretamente, el Art. 45.2 B) c) señala que tendrá carácter de suelo no consolidado aquél que precise de un incremento o mejora de dotaciones, "así como en su caso de los servicios públicos y de urbanización existentes, por causa de un incremento del aprovechamiento objetivo derivado de un aumento de edificabilidad, densidad o de cambio de uso que el instrumento de planeamiento atribuya o reconozca en parcelas integradas en áreas homogéneas respecto al aprovechamiento preexistente.

Se presumirá que este aumento de edificabilidad o densidad o cambio de uso requiere el incremento o mejora de las dotaciones, y en su caso de los servicios públicos y de urbanización, cuando dicho incremento comporte un aumento del aprovechamiento objetivo superior al diez por ciento del preexistente» ${ }^{30}$.

Nos podemos encontrar, por tanto, ante una situación en la que un Ayuntamiento se plantee desplazar urbanísticamente las viviendas turísticas fuera de los cascos urbanos de las ciudades. Lo lógico sería que a los lugares a los que se trasladen estos nuevos usos turísticos demandasen nuevas necesidades de infraestructuras o dotaciones locales llegando incluso a plantearse la posibilidad de tener que cambiar la clase de suelo urbano de consolidado a no consolidado, por ejemplo, como sucede en Andalucía. Quizás sea esta una de las consecuencias más importantes que pueda tener la adopción de medidas de zonificación para las viviendas turísticas y que no han sido suficientemente medidas por los Ayuntamientos que las han ido adoptando.

\section{CONCLUSIONES}

El sector del alojamiento turístico está provocando una auténtica catarsis en el ámbito del turismo en España. Aunque con orígenes en formas colaborativas de economía y, por tanto, sin ánimo de lucro, en la actualidad se ha conformado como uno de los sectores económicos y profesionales más pujantes y con más aceptación social.

Junto a los indudables beneficios que para la sociedad comporta esta nueva forma de prestación de servicios turísticos, se producen una serie de externalidades que deben intentar corregirse o mitigarse con

27 Véase una aplicación de este supuesto en la Sentencia del Tribunal Supremo de 12 de marzo de 2013 (RJl2013।2994).

28 «Art. 7. 1. A efectos de esta ley, se entiende por actuaciones de transformación urbanística:

b) Las actuaciones de dotación, considerando como tales las que tengan por objeto incrementar las dotaciones públicas de un ámbito de suelo urbanizado para reajustar su proporción con la mayor edificabilidad o densidad o con los nuevos usos asignados en la ordenación urbanística a una o más parcelas del ámbito y no requieran la reforma o renovación de la urbanización de éste».

29 «2. Cuando se trate de las actuaciones de dotación a que se refiere el artículo 7.1 b), los deberes anteriores se exigirán con las siguientes salvedades:

a) El deber de entregar a la Administración competente el suelo libre de cargas de urbanización correspondiente al porcentaje de la edificabilidad media ponderada de la actuación o del ámbito superior de referencia en que ésta se incluya, que fije la legislación reguladora de la ordenación territorial y urbanística, se determinará atendiendo sólo al incremento de la edificabilidad media ponderada que, en su caso, resulte de la modificación del instrumento de ordenación. Dicho deber podrá cumplirse mediante la sustitución de la entrega de suelo por su valor en metálico, con la finalidad de costear la parte de financiación pública que pudiera estar prevista en la propia actuación, o a integrarse en el patrimonio público de suelo, con destino preferente a actuaciones de rehabilitación o de regeneración y renovación urbanas.

b) El deber de entregar a la Administración competente el suelo para dotaciones públicas relacionado con el reajuste de su proporción, podrá sustituirse, en caso de imposibilidad física de materializarlo en el ámbito correspondiente, por la entrega de superficie edificada o edificabilidad no lucrativa, en un complejo inmobiliario, situado dentro del mismo, tal y como prevé el artículo 26.4, o por otras formas de cumplimiento del deber en los casos y condiciones en que así lo prevea la legislación sobre ordenación territorial y urbanística».

30 Véase, por ejemplo, la Sentencia del Tribunal Superior de Justicia de Andalucía de 14 de octubre de 2013 (JURl2014\131370). 
REALA. Nueva Época - N. ${ }^{10}$, Octubre 2018 - ISSN: 1989-8975 - DOI: 10.24965/reala.v0i10.10545 - [Págs. 6-21]

La intervención local en las viviendas de uso turístico a través de la zonificación urbanística: requisitos y consecuencias

Estanislao Arana García

la acción de los poderes públicos. En este sentido, las normas autonómicas reguladoras del turismo se han encargado de establecer una serie de medidas que regulan el ejercicio de la actividad. Pero, junto a este tipo de medidas, la Administración Local también quiere protagonismo en este sector y en el ejercicio de sus competencias, fundamentalmente las urbanísticas, y están adoptando medidas que tratan de resolver las externalidades que provoca esa actividad.

Fundamentalmente, las medidas que se están aprobando por parte de los Ayuntamientos de este país tienen que ver con la zonificación o calificación urbanística. Así, en primer lugar, al haberse convertido en una actividad económica más, el carácter residencial inicial de este tipo de viviendas no se considera el «uso urbanístico» más adecuado y se exige su ubicación en suelos de carácter terciario hotelero.

Uno de los problemas que, en primer lugar, se plantean es si este tránsito del uso residencial al terciario requiere nueva licencia urbanística por cambio de uso. La solución a esta cuestión no está clara como lo demuestra la disparidad de pronunciamientos judiciales que, en unos casos, exigen la licencia y, en otros, no la consideran necesaria. La razón de esta dificultad tiene que ver con la ausencia de regulación general en las normas urbanísticas, fundamentalmente, autonómicas de esta tradicional y antigua técnica. Respetando, por supuesto, la autonomía local y la necesaria capacidad de los Ayuntamientos para decidir los usos urbanísticos que mejor respondan a las necesidades de un determinado municipio, quizás fuesen convenientes reglas y parámetros generales que aporten más transparencia y elementos reglamos que permitan un mayor y mejor control en este ámbito.

La cuestión que jurídicamente ha planteado mayores problemas y discusiones tiene que ver con la aplicación o no de la regulación de la libertad de prestación de servicios de la Unión Europea a este caso y, especialmente, las reglas contenidas en la Directiva de Servicios de 2006 y la legislación nacional de trasposición de esta importante norma. Se cuestiona si este tipo de medidas de zonificación son medidas de carácter estrictamente urbanístico y, por tanto no les resulta aplicables las limitaciones propias de aquélla normativa. El Tribunal de Justicia de la Unión Europea ha significado que aunque se trate de medidas urbanísticas y que, por tanto, pueden ser adoptadas para controlar o regular una actividad económica, las reglas de la libre prestación de servicios son aplicables y, consecuentemente, sólo se considerarán válidas si superan el test de la no discriminación, necesidad y proporcionalidad. Habrá de analizarse caso a caso si las decisiones adoptadas por los diferentes ayuntamientos y que pretenden zonificar las viviendas turísticas están suficientemente motivadas en el sentido indicado por la normativa europea y la estrictamente nacional de desarrollo.

Finalmente, hay que tener muy en cuenta cuando se adoptan este tipo de decisiones tendentes a la zonificación del alojamiento turístico que puede ser necesario aumentar las infraestructuras y dotaciones locales al lugar al que se decida «llevar» este tipo de viviendas o residencias turísticas. En algunos casos, incluso, la consecuencia podría ser la obligación de convertir suelos urbanos consolidados en suelos urbanos no consolidados por estar necesitados de infraestructuras de dotación.

\section{BIBLIOGRAFÍA UTILIZADA}

ATXUKARRO ARRUBARRENA, I. (2017). "La regulación urbanística de las viviendas para uso turístico", en El Consultor de los Ayuntamientos, núm. 12.

BARNES VÁZQUEZ, J. (2017). "Un falso dilema: Taxis vs. Uber", en Diario La Ley, núm. 8.942, 16 de marzo de 2017.

CONTRERAS DELGADO DE COS, J. M., SILOS RIBAS, M., SOBRINO RUIZ, M. (2017). "La economía colaborativa en los sectores regulados (V). Alojamientos turísticos", en la obra colectiva dirigida por ALFONSO SÁNCHEZ, R., VALERO TORRIJOS, J., Retos jurídicos de la economía colaborativa en el contexto digital. Ed. Aranzadi.

BUSTILLO BOLADO, R. O. (2007). "Clasificación y calificación del suelo", en MARTín REBOLLO, L., y BUSTILLO BOLADO, R. O., (dirs.). Fundamentos de Derecho urbanístico. Ed. Aranzadi.

DE GUERRERO MANSO, C. (2012). La zonificación de la ciudad: concepto, dinámica y efectos. Ed. Aranzadi.

DE LA ENCARNACIÓN, M. (2016). "El alojamiento colaborativo: viviendas de uso turístico y plataformas virtuales", en Revista de Estudios de la Administración Local y Autonómica (REALA), núm. 5 (enero-junio 2016). DOI: https:// doi.org/10.24965/reala.v0i5.10350.

GUILLÉN NAVARRO, N. A. (2015). "La vivienda de uso turístico y su incidencia en el panorama normativo español", en Revista Aragonesa de Administración Pública, núm. 45-46.

HERRERO SUÁREZ, C. (2017). "Las viviendas de uso turístico: ¿El enemigo a abatir? Reflexiones sobre la normativa autonómica en materia de alojamientos turísticos", en Revista de Estudios Europeos, núm. 70, juliodiciembre de 2017. 
LORA-TAMAYO VALLVÉ, M. (2017). "Economía colaborativa y alojamiento", en La regulación de la economía colaborativa: Airbnb, BlaBlaCar, Uber y otras plataformas, obra colectiva coordinada por MONTERO PASCUAL, J. J. Ed. Tirant Lo Blanch.

RISCOS GÓMEZ, J. F., GARCíA HIDALGO, J. L., PALMA MARTOS, L. (2017). "Mejora de la regulación en la economía colaborativa. El caso de las viviendas turísticas en Andalucía", en Revista Internacional de Turismo y Empresa, vol. 1, núm. 2. DOI: https://doi.org/10.21071/riturem.v1i2.10217.

RODRIGUEZ FONT, M. (2017). "Barreras regulatorias a la economía colaborativa y nuevas vías de impugnación de normas: el caso de las viviendas de uso turístico", en Revista española de derecho administrativo, núm. 182.

RODRIGUEZ FONT, M. (2016). "La regulació de l'allotjament col-laboratiu a Catalunya: anàlisi de les propostes de l'Autoritat Catalana de la Competència", en Revista catalana de dret públic, núm. 53.

ROMERO ALOY, M. J. (2011). "La zonificación urbanística. Algunas innovaciones", Práctica Urbanística, núm. 109, Sección Estudios, noviembre 2011.

SIMANCAS CRUZ, M. R., PEÑARRUBIA ZARAGOZA, M. P., TERMES, R. (2018). "La calificación urbanística del suelo: cuestión clave en la prohibición del alquiler vacacional en las áreas turísticas de litoral de Canarias", en Cuadernos geográficos de la Universidad de Granada, vol. 57, núm. 1. DOI: https://doi.org/10.30827/cuadgeo. v57i1.5666.

SOCÍAS CAMACHO, J. M., (2018). "Estado regulador y alojamiento colaborativo. El régimen de la intervención pública limitadora de la prestación del servicio", en Revista de Administración Pública, núm. 205. DOI: https://doi. org/10.18042/cepc/rap.205.04.

YAÑEZ VELASCO, I. (1997), "Concepto de uso en la legislación del suelo (Especial referencia a la calificación y zonificación)", en Revista de Derecho Urbanístico y Medio Ambiente, núm. 156, septiembre-octubre 1997. 